\title{
THOMAS LIGOTTI: LOS DELIRIOS DE UNA MENTE ROTA ${ }^{1}$
}

\author{
Sergio Armando Hernández Roura \\ Universitat Autònoma de Barcelona \\ sergioarmando.hernandez@e-campus.uab.cat
}

Recibido: 28-01-2013

Aceptado: 03-05-2013

(c) (7) $\Theta$

\section{RESUMEN}

El presente trabajo parte de la pregunta por la pertinencia de las denominaciones que se han utilizado para clasificar la obra de Thomas Ligotti (terror filosófico, metafísico o nihilista); si estas son apropiadas para dar cuenta del trabajo de este autor o si sólo forman parte de estrategias de mercadotecnia. Para ello, partiendo del análisis de algunos de sus cuentos más representativos, en los que se presentan constantes de su obra como el sueño, la irrealidad y a las alucinaciones, se plantea un trayecto que va de lo consciente a lo inconsciente que busca explicar por medio de las teorías de lo fantástico el trabajo de este autor.

Palabras Clave: Terror, nihilismo, posmodernidad, pesadilla, onírico, delirio

\section{AbSTRACT}

This analysis inquires about the pertinence of classifying denominations that have been used for Thomas Ligotti's works (philosophical, metaphysical or nihilistic terror). The question of wether these are appropriate and useful for the author's texts or work only as a marketing strategy is developed in this article. For that purpose, some of Ligotti's most representative tales are analyzed, in these, the themes of the dream, the unreality and the hallucinations are all present. The goal is to portray one voyage from the conscience to the unconscious that pretends to explain the work of this writer using the theory of the fantastic.

KEYWORDS: Terror, nihilism, postmodernity, nightmare, oniric, delirium

1 Esta investigación fue realizada gracias al programa de Becas para Estudios en el Extranjero FONCA-CONACYT (Fondo Nacional para la Cultura y las Artes y Consejo Nacional de Ciencia y la Tecnología), Estudios Artísticos y Culturales (2012-2013). 
1. ¿TERROR FILOSÓFICO, METAFÍSICO O NIHILISTA?

El misterioso hermetismo y la excentricidad de estilo han sido factores para que Thomas Ligotti (1953) se haya convertido en un autor de culto. Sus obras pueden resultar muy extrañas para el lector que está habituado a la narrativa de Stephen King, Ramsey Campbell o Clive Barker. En oposición al tipo de textos de estos autores, la propuesta estética de Ligotti ha sido clasificada como terror filosófico, metafísico (Ortiz, 2010) o nihilista (denominación que se le da en algunas páginas de internet).

Se ha utilizado el término «filosófico» para distinguir su trabajo de un terror más comercial. ${ }^{2} \mathrm{Al}$ respecto, el crítico $\mathrm{S}$. T. Joshi coincide en señalar la originalidad de este autor en su libro The Modern Weird Tale (2001), aunque no lo separa de los escritores mencionados; su criterio de inclusión se basa en que las obras de estos autores poseen una concepción de mundo que les es muy particular y que no está presente en la mayor parte de la obras del género en la actualidad: «The purpose of modern weird writing seems to be merely to frighten. This is an inevitable result of the elimination of a philosophical basis to weird: all that is left (if, indeed, anything is left) is the emotion of horror» (Joshi, 2001: 2).

El propio Ligotti ha manifestado su desprecio por este terror comercial y se refiriere a él en la introducción a La fábrica de pesadillas, su libro de cuentos: "[La noche de los muertos vivientes] No se ha vendido a los códigos morales de guardería de casi todo el "terror moderno", y no lanza ningún mensaje concreto. Su único propósito es la pesadilla» (Ligotti, 2006: 14).

Como se verá a continuación, las denominaciones que se han utilizado para clasificar la obra de este autor carecen de una explicación que elimine la sospecha de que solo se trata de estrategias de mercadotecnia (detestadas expresamente por el propio Ligotti). Por eso, es pertinente tratar de definir su obra desde las teorías de lo fantástico, para desenmarañar la confusión de términos.

David Roas divide los efectos de lo fantástico en miedo físico o emocional, el que surge de la amenaza física y la muerte (Roas, 2006: 108), y el miedo metafísico o intelectual, que es propio del género fantástico y que «si bien suele manifestarse en los personajes, atañe directamente al lector (o al espectador), puesto que se produce cuando nuestras convicciones sobre lo real dejan de

2 El New York Times Book Review afirma que «If there were a literary genre called "philosophical horror", Thomas Ligotti's [Grimscribe] would easily fit within it... provocative images and a style that is both entertaining and lyrical» (Cardin, 2000). 
funcionar, cuando [...] perdemos pie frente a un mundo que antes nos era familiar» (Roas, 2006: 111).

Las denominación «terror metafísico» que también se ha empleado para definir la obra de Ligotti, entra en conflicto cuando se pone frente a la distinción hecha por Roas, porque si el miedo que genera la literatura fantástica es metafísico, el uso de este término no sirve para hacer la distinción de este autor con respecto al resto de obras de género fantástico, que igualmente producen «miedo metafísico». Una vez descartado el uso de esta categoría, quizá sea más conveniente el término "nihilista" para hablar del tipo específico de efecto de terror que quiere provocar, basado en la angustia existencial.

En su estudio sobre el terror moderno, S. T. Joshi introduce la obra de Ligotti por medio de una carta de H. P. Lovecraft dirigida a Robert E. Howard; en ella, el creador de los mitos de Cthulhu dio una definición para lo que denominó su etapa cuasirrealista, aquella «in which the weird is introduced subtly and gradually through the painstaking accumulation of realistic details in every aspect of the tale except that pertaining to the weird manifestation» (Joshi, 2001: 243). Como señala Joshi más adelante, la narrativa lovecraftiana estuvo lejos de escapar de los hechos concretos de la vida; sin embargo, esa noción está presente en el autor de La fábrica de pesadillas y constituye un punto de partida para su estudio: «The whole notion of escaping from life - escaping, that is, from the mundane, the actual, the real- can apply more pertinently to a recent writer, Thomas Ligotti» (Joshi, 2001: 243244). Es conveniente tener esto en mente porque ese alejamiento de lo cotidiano enfatiza la necesidad de considerar la autorreferencialidad de este autor. ${ }^{3}$ Sus historias, más allá de aludir a hechos extraliterarios concretos, tienen su base en preocupaciones y planteamientos filosóficos posmodernos.

Por ello, para plantear el carácter fantástico de este autor, es necesario recurrir a las escasas declaraciones que ha dado en entrevistas, considerar las referencias a su poética diseminadas en sus obras y contrastarlas con el análisis de algunos de su relatos más representativos: «One of Ligotti's many distinctive attributes is the frequency with which he can metafictionally enunciate his own literary agenda in his tales» (Joshi, 2001: 248). El presente acercamiento al trabajo de Ligotti tiene como base la cadena de representaciones del material fantasmático propuesto por Jean Bellemin-Noël

3 «But I am troubled by a number of things: his writing is so self-conscious and self-referential that it utterly lacks spontaneity and emotional vigor; its appeal seems directed almost wholly to the intellect; he seems, apparently by design, not to care about the complete reconciliation of the various supernatural features, in a given tales and a number of his stories» (Joshi, 2001: 257). 
(2002), esquema que permite realizar un recorrido de lo consciente a lo incosciente, de lo real a lo irreal. La pertinencia de este trayecto radica en que el autor analizado le ha dado una importancia capital al sueño, la irrealidad y las alucinaciones en la construcción de sus relatos y, en consecuencia, en la conformación de su estilo: ${ }^{4}$ «El relato de terror hace el trabajo de una especie de sueño que todos conocemos. A veces lo hace tan bien que incluso el asunto más irracional e improbable puede afectar al lector con una sensación de realismo más allá de lo realista, un truco que no suele darse más allá del vodevil que es el sueño» (Ligotti, 2006: 20).

En consecuencia, debido al carácter onírico e irreal recurrente en los textos de este autor, el análisis de su obra debe apoyarse en la utilización de categorías que den cuenta de los procesos inconscientes: «Pero si bien existen numerosos criterios que permiten distinguir los subgéneros portadores de esos fantasmas poco encubiertos, el criterio principal consiste en que los hechos que nos son contados en los relatos fantásticos reproducen o por lo menos imitan los procesos en que se basa la singularidad del inconsciente» (BelleminNoël, 2002: 53).

Bellemin-Noël utiliza la categoría fantasmática para referirse al «conjunto organizado (unificado y estructurado) de fantasmas que aparecen en un individuo, en un grupo o en un sistema de pensamiento dado» (BelleminNoël, 2001: 119), y señala que el objetivo del escritor de literatura fantástica es «llevar su desesperación del estadio de angustia ante lo Desconocido al estadio del miedo, que permite afrontar una amenaza concreta» (BelleminNoël, 2002: 52). A continuación se presenta un cuadro en el que se resume la cadena de representaciones del material fantasmático (Bellemin-Noël, 2002: 53). Este modelo teórico permite distinguir las cinco metamorfosis de la actividad psíquica por las que el fantasma pasa «cuando penetra en el campo de la consciencia» (Bellemin-Noël, 2002: 52):

\begin{tabular}{|c|c|c|c|c|}
\hline $\begin{array}{c}\text { DELIRIO } \\
\text { PSICÓtICO }\end{array}$ & $\begin{array}{c}\text { SUEÑO } \\
\text { NOCTURNO }\end{array}$ & SUEÑO DIURNO & $\begin{array}{c}\text { FANTASMAS } \\
\text { NUCLEARES }\end{array}$ & $\begin{array}{c}\text { FANTASMAS } \\
\text { ESTETIZADOS }\end{array}$ \\
\hline $\begin{array}{c}\text { LO INVEROSÍMIL, } \\
\text { IMPENSABLE, } \\
\text { IMPOSIBLE DE } \\
\text { IMAGINAR }\end{array}$ & SUEÑOS & FANTASÍAS & $\begin{array}{c}\text { MITOS, LEYENDAS, } \\
\text { CUENTOS DE HADAS, } \\
\text { HISTORIAS FANTÁS- } \\
\text { TICAS }\end{array}$ & $\begin{array}{c}\text { LITERATURA Y Y } \\
\text { ARTES PLÁSTICAS }\end{array}$ \\
\hline
\end{tabular}

4 «The focus of all Ligotti's work is a systematic assault on the real world and the replacement of it with the unreal, the dreamlike, and the hallucinatory» (Joshi, 2001: 245). 
Como se observa en este esquema, Bellemin-Noël parte de lo subjetivo para ir hacia la objetivización del material fantasmático e incluso, como se verá a continuación, puede ser un punto de partida para comprobar que una clara intención de Ligotti consiste en dar cuenta del camino inverso, tomar como punto de partida los fantasmas estetizados ${ }^{5}$ para desplazarse poco a poco en un sentido contrario. ${ }^{6}$ Para ese efecto se ha seleccionado algunas de las narraciones que permiten ejempli ficar su viaje al delirio.

\section{Pinceladas De irRealidad: «El Retozo» Y «La Última aVentura de Alicia»}

En «El retozo», el psiquiatra de una penitenciaría charla con su mujer sobre la inquietud que le despierta uno de sus pacientes, un hombre encerrado por el misterioso robo de niños en circunstancias no resueltas. El individuo, caracterizado por su cinismo y frialdad, responde enigmáticamente a todos los cuestionamientos, como si se tratara de un ser de otro mundo al que lo humano le es indiferente. El médico se encuentra preocupado sobre todo porque el extraño personaje conoce detalles de su vida privada que es imposible que supiera, además de que su esposa, buscando realizar una buena acción, ha comprado una estatuilla que coincidentemente ha sido modelada por su paciente con la forma de la cabeza de una de sus víctimas. Ella intenta tranquilizarlo. Después de tener esta plática deciden ir a la habitación de su hija para revisar que todo está en orden, pero descubren que ha desaparecido. Confirman así el carácter sobrenatural del ser que se ha robado a su hija.

Como es posible observar a lo largo del relato, Thomas Ligotti combina la figura del asesino serial con las entidades lovecraftianas, dos fantasmas estetizados y ya muy enraizados en la cultura actual. Lo que comienza siendo un cuento con un estilo semejante al de Stephen King, con la representación de un mundo cotidiano acentuado por la trivialidad de los primeros diálogos,

5 «[...] al final de esta cadena de representaciones del material fantasmático, se encuentran las obras de ficción de tono realista, tanto en lo que hemos dado en llamar la gran literatura como en las artes figurativas; es aquí donde encontramos por así decirlo los fantasmas estetizados» (Bellemin-Noël, 2002: 53).

6 Él mismo ha externado su interés por alejarse de ellos al referirse a lo que ha pasado con la figura del vampiro: «Consequently, the vampire was stripped of all that made him alien to our ordinary selves, until he was transformed into merely the bad boy next door. He remained a menace, to be sure, but his focus shifted from the soul to the senses. This is how it is when a mysterious force is embodied in a human body, or in any form that is too well fixed. And a mistery explained is one robbed of its power of emotion, dwindling into a parcel of information, a tissue of rules and stadistics without meaning in themserves», y al mismo tiempo prefiere algo más abstracto e informe, como la oscuridad: «It is also extremely abstract as a provenance for supernatural horror, an elusive prodigy whose potential for fear may slip through a writer's fingers and right past even a sensitive reader of terror tales. Obviously is problematic in a way that a solid pair of gleaming fangs at a victim's neck is not» (Ligotti, 2003: 79). 
se convierte poco a poco en una pesadilla que comienza a manifestarse en el lenguaje:

David sintió cómo sus palabras alteraban la atmósfera del salón, contaminando la serenidad de la casa. Hasta entonces su hogar había sido un refugio insular alejado de la polución de la prisión, una imponente estructura fuera de los límites de la ciudad. Ahora su imposición física trasgredía los límites de la distancia física. Las distancias interiores se constreñían, y David sentía cómo los gruesos muros de la penitenciaría oscurecían el acogedor vecindario (Ligotti, 2006: 24).

Para construir el efecto de lo fantástico, el autor se sirve de la indefinición del paciente: «Pero según él tiene muchos nombres, no menos de mil, ninguno de los cuales ha consentido en pronunciar en presencia de nadie. Desde mi punto de vista, en realidad no tiene necesidad alguna de un nombre humano» (Ligotti, 2006: 24). El convicto poco a poco se va desdibujando y se va convirtiendo en un ser numinoso. Así lo explica el psiquiatra a su esposa:

-Imitas muy bien a ese John Doe.

-Muchas gracias, pero no podría mantenerlo mucho tiempo. No sería fácil imitar todas sus voces diferentes y todos sus niveles de falta de articulación. Podría ser algo que se acercara a la personalidad múltiple (Ligotti, 2006: 27).

La inestabilidad del mundo se manifiesta en la erradicación de las fronteras de la concepción del individuo. Un ser múltiple, atemporal, sin espacio o tiempo fijos irrumpe en la cotidianidad del psiquiatra para agregar una víctima a su colección de «retozos», como denomina a los niños desaparecidos.

Se ha planteado un cuento fantástico con una estructura tradicional, ${ }^{7}$ en la que la posibilidad de que los límites, tanto físicos (prisión) como metafísicos (lenguaje), ya no son garantía de seguridad.

«La última aventura de Alicia» narra el proceso de deterioro mental de una escritora de cuentos macabros para niños a causa del alcohol y la depresión; factores que sirven como puente para que los personajes creados por ella irrumpan en el mundo real. Esta narración es una alusión a Alicia a través del espejo de Lewis Caroll, y se centra en las alteraciones de la percepción: «Es como mirar uno de esos cuadros de juguete que muestran dos escenas distintas según la forma en que los muevas, pero, en un determinado ángulo, mues-

7 Llamaré relato fantástico tradicional a aquel que tuvo su origen en el mundo ilustrado, caracterizado por poseer una concepción racional y mecanicista del mundo, y que tiene por objeto mostrar cómo la irrupción de lo imposible puede trastornar la estabilidad de esa realidad. Véase Roas (2001). 
tran la mancha borrosa de ambos a la vez» (Ligotti, 1989: 169). La distorsión del mundo hace que la protagonista dude de su concepto de realidad y de su propia existencia: «Suceda cuando suceda, siempre será el reflejo, antes que nada la imagen sesgada o ilusoria... y después el eco de la vida real» (Ligotti, 1989: 169). Al final del relato, el personaje y el espectador comparten la misma duda: ¿se está adentro o afuera del espejo?: «Debo confesar que las fases lunares ("fases lunáticas", como decía Preston) no me interesan, pero algo parece haber cambiado desde la última vez que atisbé por la ventana: parece que esa cosa se haya invertido. Si antes era cóncava hacia la derecha, ahora parece convexa en esa dirección, el último cuarto transformado en el primer cuarto, o algo así» (Ligotti, 1989: 167).

Nuevamente Ligotti se sirve de la descripción para presentar un mundo anómalo: «Como la escritura que solo puede leerse mediante un espejo, las formas que acechan detrás de la ventana —árboles, casas, aunque, gracias a Dios, no hay ni rastro de gente- aparecen desagradables y erróneas» (Ligotti, 1989: 167); pero eso únicamente es el preludio del momento más inquietante, la aparición de Preston: «Nunca oí su risa, excepto en mi imaginación, pero suena exactamente como yo imaginaba» (Ligotti, 1989: 169).

Como observamos, en este caso, Ligotti crea el efecto de lo fantástico por medio de la irrupción de lo ficticio en el mundo real a través de los resquicios de la mente: «Hace largo tiempo que existe una conexión entre la locura y el terror sobrenatural. Una mente rota es con frecuencia la vía hacia un mundo insospechado por aquellos de una inocente normalidad. De forma recíproca, lo sobrenatural puede invadir nuestro mundo mediante un portal proporcionado por un cerebro defectuoso» (Ligotti, 2007: 49).

Ambos relatos ejemplifican los fantasmas estetizados, aunque en el segundo de ellos se presenta un desplazamiento al siguiente estadio, el de los fantasmas nucleares, perteneciendo así también al apartado siguiente.

\section{SUEÑOS OSCUROS: «EL DOCTOR VOKE Y EL SEÑOR VEECH» Y «SEVERINI»}

En «El doctor Voke y el señor Veech», Ligotti introduce el tema de los títeres; obsesión a la que se refiere en la introducción a «El sueño de un maniquí», uno de sus relatos adaptados a cómic:

De hecho, por regla general en la mayoría de los casos, las muñecas, maniquís, títeres y marionetas son atrezzo desperdigado por toda una historia de fantasmas, rostros rígidos vislumbrados a la luz de la luna que entra en la habitación de un niño, brazos y piernas desmembrados, o cabezas decapitadas que anteriormente adornaron el escaparate de 
la tienda de juguetes y que desde entonces han sido relegados a piezas sueltas diseminadas por un viejo almacén donde se guardan cosas semejantes o se les lleva a morir. En esta calidad, tienen un buen valor simbólico, ya que parecen estar vinculados a otro mundo, uno en el que todo es dolor y desorden; la clase de lugar que a veces tememos que sea el modelo de nuestro propio mundo, que básicamente creemos seguro, o al menos uno en el que no confundimos una falsificación de persona con una auténtica. [...] La lección: ninguno de nosotros puede estar realmente seguro de qué somos o en qué podemos convertirnos (Ligotti, 2007: 35).

Esta afirmación permite comprender mejor lo que ocurre en «El doctor Voke y el señor Veech». En esta narración, el lector se ubica in medias res en un ambiente que ya no pertenece a los fantasmas estetizados, los fantasmas nucleares ${ }^{8}$ y que ya se encuentra en el ámbito del sueño nocturno 9 . Ligotti ha tomado los títeres como un ejemplo de fantasmas estetizados para conducir al lector hacia el sueño nocturno. El señor Veech le pide al doctor Voke, un titiritero, que lo ayude a resolver sus problemas amorosos: el triángulo termina con su enamorada y el amante de ella convertidos en un títere andrógino mientras caminan por una oscura callejuela. Cuando Veech reclama lo sucedido a Voke, es jalado por unos misteriosos hilos, en tanto que este, quien hasta entonces parece estar detrás de todo, se suicida tirándose por las escaleras. El tema de esta narración de acciones imprevisibles es la libertad. Su carácter ambiguo viene de la imposibilidad de saber si el doctor Voke se ha suicidado intencionalmente o si se trata de un designio superior:

Voke se pone en pie con el poder de su hilaridad idiota. Empieza a ir de un sitio a otro bailando de forma extraña, saltando a la pata coja, botando, meneándose. Su risa se hace aún peor mientras gira sin rumbo fijo y sus gestos se hacen más convulsos. Sin prestar la más remota atención, o tal vez recuperándola por un momento, Voke sale del desván y ahora ríe en el oscuro abismo más allá de la barandilla precaria al final de la sinuosa escalera (Ligotti, 2006: 115).

\footnotetext{
8 «[La] realización individual caprichosa encuentra un garante colectivo en los relatos donde los humanos comparten sus fantasmas nucleares: los mitos, las leyendas, los cuentos de hadas, las historias fantásticas, ya sea en la escritura, el cine o el cómic; estos fantasmas se denominan "originarios" porque son universales y giran en torno a la cuestión del origen, es decir, de nuestro nacimiento y de lo que lo ha precedido. Mediante estos relatos, a menudo orales, las sociedades humanas colectivizan su imaginario y construyen un fundamento ideológico para el grupo» (Bellemin-Noël, 2002: 53).

9 «[...] un conjunto de imágenes a menudo divertido o absurdo pero que presenta una especie de intriga - Freud habla de una "fachada" narrativa - que yuxtapone de forma caótica episodios aproximadamente incoherentes, de modo que un análisis detallado puede acabar con su opacidad restaurando un orden casi razonable» (Bellemin-Noël, 2002: 53).
} 
Las últimas líneas de la narración son reveladoras ya que, al parecer, el único ser vivo en ese mundo es un muñeco, ${ }^{10}$ que en un primer momento se presenta como parte del decorado siniestro y que luego se convierte en una metáfora de la insignificancia de la condición humana:

De esta manera, los gritos que ahora oímos no son aquellos del Voke que caía en picado, ni tampoco los de Cheev que hace tiempo que se fue, ni los ecos sobrenaturales de los gritos de terror de Prena y Lamm. Estos gritos, los que se oyen más allá de la puerta al final de las escaleras, pertenecen solo a un muñeco, que siente cómo unas gotas calientes de sangre le resbalan con densidad sobre las mejillas lacadas, y al que han dejado solo y vivo en las sombras de un desván abandonado. Y sus ojos dan vueltas como canicas (Ligotti, 2006: 115).

Es necesario señalar que este cuento plantea un problema para definir lo fantástico ya que las acciones siempre tienen lugar en la irrealidad. Es posible notar que el objetivo del autor es mostrar que la realidad en la que se mueven los personajes es ficticia y que sus papeles en la existencia son insignificantes, cuestionamiento que no deja de tocar al lector. En todo caso, desde un punto de vista clásico, lo fantástico ocurre por medio de una anagnórisis, de que nadie carece de hilos.

«Severini» narra la influencia y obsesión que despierta el extraño personaje que da nombre al cuento; combinación entre gurú, mago y mecenas, en los que lo conocen y particularmente en el narrador, quien nunca se relaciona directamente con él sino a través de las obras de arte que inspira o por los comentarios de otras personas:

Aunque tengo dificultades para recordar la obra que se corresponde con cada título - ya sea una pintura o una escultura, un poema o una pieza teatral一, todavía soy capaz de mencionar algunos. Uno de los que recuerdo con facilidad es Sin cara entre nosotros. Un título semejante a este es Profanado y liberado. Y ahora me vienen a la cabeza algunos otros: El camino de lo perdido, En suelo sagrado y viscoso (también conocido como Los doctores tántricos), En tierra y excrementos, La negra espuma de la existencia, Tegumentos en erupción y El descenso hacia los hongos. Todos esos títulos, según me informaron mis conocidos artistas y socios, derivaban de frases (o fragmentos) seleccionadas que Severini había pronunciado durante sus numerosos episodios de somniloquio (Ligotti, 2006: 268).

10 Así lo da a entender el doctor Voke: «La pregunta no es por qué se ríe, en absoluto. La pregunta es de dónde viene esa risa. En realidad, eso es lo que da miedo. El muñeco lo aterroriza, pero es él quien de verdad está atemorizado. Píenselo: la madera se despierta. No se lo puedo poner más claro» (Ligotti, 2006: 109-110). 
El personaje intuye que Severini posee un poder esotérico con el que controla a las personas, ${ }^{11}$ y teme cuando recibe la invitación que le hace este extraño personaje para que lo conozca. En un estado febril cree percibir su llamado hipnótico. La narración termina con la destrucción de la casa de Severini con todos sus seguidores adentro provocada por el protagonista, quien no deja de pensar en la posibilidad de que todo haya estado en su mente:

Nunca volví a verlos después de aquella noche, porque aquella noche se los llevó consigo a la pesadilla, con el parpadeo de la llama de la vela sobre aquellas obras de arte y las variaciones de forma que a los otros les parecían un nido de serpientes retorcidas o una masa de arañas recién incubadas. Les mostró la entrada a la pesadilla, pero no pudo enseñarles la salida, pues no existe una vez te has adentrado tanto en sus profundidades. Allí fue donde se perdió para siempre, él y los otros que se llevó consigo (Ligotti, 2006: 275).

La disolución de la identidad es una de las nociones que hacen muy característico este relato, la interconexión entre Severini y el narrador, en un acto de ventriloquía que emparenta este relato con «El doctor Voke y el señor Veech».

Es necesario hacer notar dos particularidades de esta narración, muestra de otro fantasma nuclear, la idea de que el lenguaje es un medio de distorsionar la realidad (de tal suerte que las creaciones de Ligotti están cada vez más cerca del delirio psicótico); y la introducción del concepto de somniloquio, estilo con el que se expresan Severini y el propio Ligotti, que tiene mucho de sueño nocturno como es posible notar en la descripción de las sensaciones que las obras inspiradas por Severni ocasionan en el protagonista:

Un elemento central de tales episodios era la impresión de encontrarme en un lugar cuyas características recordaban, por una parte, a un paisaje tropical y, por la otra, a una cloaca común. La cuestión de la alcantarilla surgía de la percepción de un espacio cerrado, pero a la vez muy extenso, una red de pasillos enroscados que abarcaban distancias increíbles en un mundo subterráneo de oscuridad neblinosa. Respecto a la cualidad de un paisaje tropical, también compartía mucho de esa especie de fermento misteriosamente supurante de la alcantarilla, pero se le añadía la impresión de las más exóticas formas de vida que se reproducían por todos lados, criaturas que se multiplicaban y que también mutaban sin cesar como una película con tomas a intervalos prefi-

11 «Tan dados a especular como eran, parecía que esta persona incoherente, todo menos anónima, conocida como Severini, estuviera sujeto a lo que se referían de varias maneras como un "proceso esotérico" o una "práctica ilícita"» (Ligotti, 2006: 268). 
jados de hongos que se propagan o moho de limo multicolor totalmente ilimitado en su forma o expansión (Ligotti, 2006: 267).

\section{EL LABERINTO ONÍRICO: «LA ESCUELA NOCTURNA» Y «TEATRO GROTTESCO»}

«La escuela nocturna» es un relato circular en primera persona de un paseo nocturno del que no es posible saber más allá de las acciones que se narran. Después de ir al cine, el protagonista decide tomar un atajo por la escuela huyendo del frío. Al llegar a este lugar su caminata comienza a tener un regusto de lo familiar y a la vez de lo desconocido, pues aunque el personaje afirma que tiene mucho tiempo de no ir por ahí, asume que se le ha hecho tarde para entrar a clase; además de que tiene encuentros con compañeros cuyos diálogos no responden a la lógica de la vigilia. Todo gira en torno al profesor Carniero [sic], quien, como afirma un compañero, «es portugués [...] pero ha vivido en casi todas partes» (Ligotti, 2006: 188). A lo largo de su trayecto, mientras se dirige al aula en la que da clases, el personaje se entera de que el profesor, quien acostumbra anotar «símbolos desconcertantes» (Ligotti, 2006: 189), ha dejado la escuela, ha regresado, ha enfermado y ha muerto. Es entonces cuando percibe lo numinoso: las voces y murmullos que ha estado escuchando y que pueden tomarse como parte de su mente no son sino el profesor Carniero:

El profesor murió de noche, ¿sabe? Está con la noche. ¿Oye las voces? Están con él. Todos están con él y él está con la noche. La noche se ha extendido por su interior y la enfermedad de la noche ha propagado su oscuridad. Él que había estado en todos sitios, puede ir a cualquier lugar con la enfermedad de la noche que se propaga. Escuche. El portugués nos llama (Ligotti, 2006: 195).

Es en ese punto cuando el personaje se da cuenta de que la expresión «Mire aquí» que escucha es la misma que el profesor usaba «normalmente mientras señalaba a algunos de nosotros que no había prestado atención a los diagramas que creaba sin cesar en la pizarra» (Ligotti, 2006: 188). La oscuridad devora al protagonista. Este se encuentra nuevamente en la entrada de la escuela, casi al principio de la narración, y decide volver sobre sus pasos; sin sospechar que la pesadilla no ha concluido.

El ambiente es onírico de principio a fin y sumerge al lector completamente en el sueño nocturno. Esta experiencia se caracteriza por su horizonte indiscernible ( Advertí que en una parte esas nubes caían hacia los árboles y se deslizaban hacia un estrecho riachuelo por la pared de la noche. Pero en 
realidad era humo denso y sucio lo que se elevaba hacia el cielo»; Ligotti, 2006: 187), en el que la realidad se torna siniestra a medida que la lectura avanza:

Incluso las nubes sobre las que la luna proyectaba su resplandor eran finas o estaban corrompidas, deshechas por algún proceso de degeneración en la atmósfera más elevada en el recinto de la escuela. También había un olor a corrupción, una fragancia encantadora - como el de la putrefacción del mantillo en otoño o en los primeros días de primavera- que pensé que salía de la tierra mientras yo perturbaba los restos extraños esparcidos arriba (Ligotti, 2006: 189).

El personaje y el lector no saben de dónde vienen ni a dónde van. El primero, sumergido en la irrealidad, asume con naturalidad cosas que se mani fiestan, en tanto que el segundo, en estado de vigilia, percibe su lado siniestro, como en el caso de este encuentro:

Estaba vestido con ropas sucias de trabajo y casi armonizaba con las sombras, tan abundantes aquella noche en la escuela. Lo detuve antes de que pasara por mi lado arrastrando los pies. Se giraron hacia mí indiferentes un par de ojos amarillentos en un rostro delgado y una tez tosca e irregular. El hombre se rascó la parte izquierda de la frente y se le cayeron algunos trozos de piel seca.

— ¿Me podría decir dónde imparte el profesor Carniero esta noche?- le pregunté.

Se me quedó mirando durante unos instantes y apuntó con un dedo al techo:

—Arriba—, contestó (Ligotti, 2006: 192).

Esta narración pretende imitar el funcionamiento irracional característico de los sueños: los pensamientos del narrador por momentos no corresponden a una lógica de causa y efecto («Allí donde fuera que se impartiera la clase, todavía necesitaba papel para tomar apuntes, transcribir los diagramas, etcétera; y no podría conseguirlo si me quedaba en aquella aula donde todos y todo estaba degenerando en la oscuridad de alrededor»; Ligotti, 2006: 192) y se da por hecho que se conocen personas a las que nunca antes se ha visto («En las escaleras que llevaban al tercer piso vi al primero, un joven sentado en los peldaños inferiores que había sido uno de los alumnos más aplicados del profesor. Estaba absorto en sus pensamientos y no me miró hasta que le hablé»; Ligotti, 2006: 194).

Cuando se piensa que el viaje ha terminado y se cree que todo ha sido una fantasía, una alucinación, una ensoñación o un sueño diurno, ${ }^{12}$ las últi-

12 «En el centro de este sistema se encuentra el sueño diurno (Tagtraum), que, en el interior de cada 
mas líneas delatan el carácter onírico de la existencia de ese personaje. Es el lector quien percibe con horror la imposibilidad ya no de salir de la pesadilla, sino la de no tener consciencia de que se está dentro de una:

Mientras caminaba bajo las farolas, cerré la parte delantera de mi abrigo con las manos y traté de mantener la mirada sobre la acera que tenía ante mí. Pero podía haber oído una voz que me pidiera «mire aquí», porque de hecho miré, aunque tan solo fuera un instante. Luego alcé la vista hacia el cielo y vi que no estaba nublado y que la luna llena brillaba en el oscuro estanque del espacio. Relucía brillante y borrosa, como si estuviera cubierta por un moho luminoso que flotara como una lámpara en las grandes alcantarillas de la noche (Ligotti, 2006: 196).

Al igual que en «Severini», «La escuela nocturna» gira en torno a la búsqueda de un personaje que solo se conoce de oídas, el profesor Carniero («Todavía no me había tocado el turno para que el profesor Carniero me ordenara mirar los jeroglíficos de la pizarra y lo comprendiera todo, por lo que aún no entendía las doctrinas de un programa realmente séptico, la ciencia de una patología ancestral, filosofía de una enfermedad absoluta, la metafísica de cosas que caen en una desintegración común o se elevan, confluyen en su oscura putrefacción»; Ligotti, 2006: 193); objetivo que fracasa incluso debido a que su identidad es nebulosa:

-Bueno, ¿podría decirme si había deberes?

-Es muy posible, nunca se sabe con este profesor. Es portugués, ya sabe, pero ha estado en muchos sitios y sabe de todo. Creo que está loco. El tipo de cosas que enseña le podrían traer problemas en algún sitio, y es probable que ya le haya pasado. No es que le preocupe lo que les ocurra a él o a otros, quiero decir, a aquellos en los que influye, y en algunos más que en otros. Las cosas que nos dice, las lecciones de medición de las fuerzas cloacales, el tiempo como una corriente de aguas residuales, el excremento del espacio, la escatología de la creación, el vacío de uno mismo, la mugrienta integración completa de las cosas y el producto nocturno, como él lo llama, que cubre los estanques de la noche... (Ligotti, 2006: 191).

Por otro lado, la búsqueda de una entidad metafísica conocida como «Teatro Grottesco», en el cuento del mismo nombre, cuyas características cambian de acuerdo con la percepción que cada persona tiene de ella y que es

uno y a merced de su propia fantasía, es el prototipo de eso que llamamos fantasma (Phantasie, en alemán), o lo que es igual, el modelo de la actividad propia de imaginación (Phantasie, también)» (Bellemin-Noël, 2002: 53). 
imposible de definir, conduce al protagonista a la destrucción mental. En esta narración el horror es generado por la idea de que la metafísica termine adueñándose del individuo, como se observa en la nota que el protagonista recibe al final: «Para terminar, espero de corazón que considere seriamente la oferta de unirse a nosotros. Podemos hacer algo respecto a su predicamento médico. Podemos hacer prácticamente cualquier cosa. En caso contrario, me temo que lo único que podré hacer será darle la bienvenida a su propio infierno privado, que será tan horroroso como pueda imaginárselo» (Ligotti, 2006: 90). Esta entidad inasible, dinámica e indefinible que en uno de los testimonios aparece descrita como algo que no es ni bajo ni alto y que no está ni cerca ni lejos, tiene la única característica estable de que destruye la capacidad creativa de los artistas. ${ }^{13}$ Nunca queda claro hasta qué punto los rumores o las especulaciones son parte de lo que realmente es el «Teatro»:

\begin{abstract}
¿Pero qué se quería decir con «cosa del Teatro»? Aquella era una expresión que había oído decir a varias personas, no todas ellas artistas del tipo pretencioso o dramático. Desde luego no faltan anécdotas que han circulado de un lado a otro tratando de explicar la naturaleza y funcionamiento de esta «troupe cruel» un epíteto empleado por aquellos demasiado supersticiosos para llamar al Teatro Grottesco por su nombre. Pero otra cosa muy distinta es hacer encajar todas esas historias en un informe coherente, por no hablar de fiel a la verdad (Ligotti, 2006: 76).
\end{abstract}

A lo largo de la narración hay breves cristalizaciones del «Teatro» que no dejan por ello de ser enigmáticas, como por ejemplo la esfera que recuerda «El Aleph» de Borges («¿Qué eran aquellas cosas que veía el doctor Groddeck? A mí me parecían diminutas flores con forma de estrella dispersas uniformemente por todo el volumen, los típicos elementos que prestan una falsa apariencia artística a un pisapapeles vulgar»; Ligotti, 2006: 88) o los múltiples nombres con los que se le conoce, enumerados por uno de sus miembros al final de la narración y que en vez de ser esclarecedores aumentan la confusión e imposibilitan cualquier intento de definir de qué se trata, en una operación semejante a la que emplea Kafka en su cuento titulado «Ante la ley»: «Nuestra compañía es más antigua que su propio nombre, o que cualquier otro nombre, ya puestos. (Y cuantos ha tenido a lo largo de los años: Las Diez Mil Cosas, Anima Mundi, Nethescurial)» (Ligotti, 2006: 90).

13 «En cierto modo todo aquel asunto del Teatro había conseguido hacer mella en nuestros nervios; se había quebrado el equilibrio entre una locura que nos embriagaba y otra que comenzaba a amenazar nuestras mentes» (Ligotti, 2006: 78). 


\section{LA MENTE ROTA: «EL BUNGALOW»}

Aunque el cuento titulado «El bungalow» no pertenece al ámbito de lo fantástico, es importante mencionarlo porque trata de un desajuste mental que permite ejemplificar el paso al delirio psicopático, una experiencia imposible de narrar con un lenguaje racional pero tematizada.

En esta narración, Ligotti lleva al extremo la identificación entre el artista y el espectador. El protagonista queda impresionado por una serie de grabaciones encontradas en una galería de arte contemporáneo que tocan su sensibilidad. Las obras tituladas El bungalow (más silencio) y La fábrica abandonada le despiertan ciertas evocaciones que lo hacen identificarse con el artista. La disociación de su mente le impide ver que se ha identificado consigo mismo y que ha creado y puesto en exhibición ambas obras para que sea él quien las contemple. Lo espeluznante es que, después de asesinar a la dueña de la galería, el personaje no cobra consciencia de su problema mental, del que solo es testigo el lector.

\section{LO FANTÁSTICO EN LIGOTTI}

Como se ha visto, los dos primeros cuentos, «El retozo» $\mathrm{y}$ «La última aventura de Alicia», se mueven en el ámbito de los fantasmas estetizados; el primero plantea un personaje cuya identidad se va haciendo cada vez más numinosa, en tanto que en la segunda, observamos una irrupción de lo ficticio en el mundo real (a lo que además habría que agregar el hecho de entrar en el espejo). En «El doctor Voke y el señor Veech» y «Severini», los ambientes oníricos sirven para plantear el problema de la pérdida de la identidad (en la primera, asociada a la figura del títere y, en la segunda, a la hipnosis). Tanto en «La escuela nocturna» como en «Teatro Grottesco» el lector es conducido por una experiencia de sueño nocturno que se aproxima al delirio psicótico. ${ }^{14}$ Además de lo que ya se ha dicho, es posible constatar que en algunas narraciones el interior invade el exterior («La última aventura de Alicia», «La escuela nocturna», «El Bungalow», «Severini») y, en otras, que el exterior invade el interior («Teatro Grottesco», «El retozo»). La cadena de representaciones del material fantasmático permite observar que algunas de estas narraciones

14 «El delirio psicótico, que no tiene en cuenta las existencias de la realidad y tolera una total incoherencia; aquí el disfraz es absoluto, puesto que obedece a una lógica secreta (propia de un sujeto particular en un momento preciso de su vida interior, y en ese sentido, imposible de reconstruir), a veces incluso se trata de la expresión descarnada de un deseo inconsciente, algo tan inverosímil por su inhumanidad que se hace literalmente impensable, imposible de imaginar» (Bellemin-Noël, 2002: 53). 
son problemáticas para definir lo fantástico desde una perspectiva tradicional porque sus planteamientos y técnicas son semejantes a las que utilizan Beckett, Buzzatti, Kafka y Borges (Schweitzer, 2003: 23).

Dos claves para considerar los cuentos de Ligotti como textos fantásticos son el papel que el lector juega en ellos ${ }^{15}$ y su concepción de que «lo sobrenatural puede considerarse la contrapartida metafísica de la locura y, como tal, es el distintivo de la pesadilla extraña de una mente consciente atrapada durante un breve tiempo en esta casa encantada que es un universo» (Ligotti, 2007: 49). A dichas características se deben sumar los temas recurrentes en su obra:

On a more philosophical note, we can discern three primary themes (although they are certainly not the only ones) emerging from a survey of Ligotti's oeuvre: first, the meaninglessness - or possibly malevolence- of the reality principle behind the material universe; second, the perennial instability of this universe of solid forms, shapes, and concepts as it threatens to collapse or mutate into something monstrous and unforeseeable; and third, the nightmarishness of conscious personal existence in such a world (Cardin, 2000: s. p.).

Como ya se ha adelantado, para definir lo fantástico en textos como «La escuela nocturna», «Teatro Grottesco», «Severini» y «El doctor Voke y el señor Veech», es necesario enmarcarlos dentro del tipo de producciones que se han hecho en el siglo XX:16

Así pues, aunque en la narrativa fantástica del siglo XX el narrador y los personajes no siempre manifiestan abiertamente su desconcierto, no cabe duda, como advierte Reis, de que «el lector concreto, exactamente a causa de ese silencio, al confrontar los acontecimientos fantásticos con los parámetros suministrados por la realidad, constata su incompatibilidad. Lo fantástico produce una ruptura, al poner en conflicto los precarios contornos de lo real cultural e ideológicamente establecido» (Roas, 2001: 39-40).

\footnotetext{
15 Ligotti expresa la importancia que esta idea tiene en su estética en la introducción a sus cuentos: «Nada es peor que aquello que le sucede a uno en persona. Y aunque un mal sueño puede llegar muy alto temporalmente en el asustómetro, siendo realistas es uno de los más pequeños y efímeros terrores a los que una persona tiene que enfrentarse. Prueba a encontrar solaz en las cinco veces que has visto $\mathrm{La}$ matanza de Texas cuando te están preparando para una operación de cirugía cerebral» (Ligotti, 2006: 13). 16 «A mi entender, lo que caracteriza a lo fantástico contemporáneo es la irrupción de lo anormal en un mundo en apariencia normal, pero no para demostrar la evidencia de lo sobrenatural, sino para postular la posible anormalidad de la realidad, lo que también impresiona terriblemente al lector: descubrimos que nuestro mundo no funciona tan bien como creíamos, tal y como se plantea en el relato fantástico tradicional [...]» (Roas, 2001: 37).
} 
Considerando esta definición de lo fantástico y el papel del lector, es necesario subrayar la importancia de los personajes creados por Ligotti, a pesar de que parecen cortados con la misma tijera: ${ }^{17}$ «Human characters, indeed, are virtually insignificant in themselves in his work, serving only as embodiments of or conduits to the unreal» (Joshi, 2001: 244).

La naturaleza de los sueños le sirve a este autor para sugerir preocupaciones posmodernas como la disolución de la identidad, la realidad como construcción y la relación entre el lenguaje y el sentido: «Lo que parece deducirse de las opiniones de Alazraki, y también de Todorov, es que la literatura fantástica contemporánea se inserta en la visión posmoderna de la realidad, según la cual el mundo es una entidad indescifrable. Vivimos en un universo totalmente incierto, en el que no hay verdades generales, puntos fijos desde los cuales enfrentarnos a la realidad: el "universo descentrado" al que se refiere Derrida» (Roas, 2001: 36).

Incluso es posible referirse a las creaciones del autor de La fábrica de pesadillas con el mismo término que Bellemin-Noël emplea para describir lo que ocurre en el cuento de Théophile Gautier «La muerta enamorada». En ambos autores hay una percepción esquizofrénica que es generada por la incapacidad de distinción entre el sueño y la vigilia (Bellemin-Noël, 2001: 122-123).

Los ambientes oníricos, además, permiten a Ligotti eliminar los límites entre natural y sobrenatural, adentro y afuera, arriba o abajo, principio o final; característica que permite subrayar su vena posmoderna: ${ }^{18}$ "Así, la diferencia reside en que lo fantástico problematiza los límites entre la realidad y la irrealidad (o la ficción), mientras que la narrativa posmoderna (hablo en un sentido muy general) los borra, $\mathrm{y}$, por tanto, armoniza lo que identificaríamos como real e imaginario» (Roas, 2008: 78).

Lo fantástico en este autor pretende llevar la irrupción de lo imposible a un plano en el que ambas realidades no se sobreponen sino que se combinan: «Accordingly, Ligotti's literary goal is to suggest that other realm which we glimpse either through dreams or, worse, stumble upon by accident in obscure corners of this world» (Joshi, 2001: 245).

Otra característica relacionada con la importancia que el autor da a los sueños es el tema de la ausencia de sentido, la cual corresponde a uno de los últimos giros que ha tomado la literatura fantástica, «el paso de lo fantástico como fenómeno de percepción [...], propio del siglo XIX, a lo fantástico como

17 «A lot of the names I use signify the nothingness of the character who bears the name and have the word "no" buried in them» (Ayad, 2004).

18 Esto también ha sido señalado por Cardin (2003) y Dziemianowicz (2003). 
fenómeno de escritura, de lenguaje»(Roas, 2001: 41). Al respecto, Rosalba Campra afirma que «Ya no es tanto la aparición del fantasma lo que cuenta para definir un texto como fantástico, sino más bien la irresoluble falta de nexos entre los distantes elementos de lo real» (citado en Roas, 2001: 41).

La importancia de los procesos inconscientes, no solo en términos de trama, sino también de lenguaje, y por lo mismo la lectura de este escritor, plantea un reto: «el habla del inconsciente no aspira a comunicar, es una eflorescencia semejante al objeto estético, 'cumple un deseo'» (Bellemin-Noël, 2001: 114); por ello, quizá sería más adecuado emplear las nociones de somniloquio («Severini») o monólogo onírico («El bungalow») que el propio Ligotti ha empleado para denominar esa particular manera de escribir:19

Por lo tanto, a menudo era muy dado a hablar de sí mismo mediante parábolas ambiguas y metáforas, por no mencionar las anécdotas inauditas cuyos hechos siempre parecían anularse los unos a los otros y las mentiras descaradas que, a veces, él mismo exponía más tarde como tal. Pero la mayoría del tiempo — según la opinión de algunos, todo el tiempo-, el discurso de Severini se convertía en un total absurdo, como si hablara en sueños (Ligotti, 2006: 266).

El estilo de este escritor ha sido destacado tanto para bien como para mal: S. T. Joshi celebra el dislocamiento del lenguaje ligottiano ${ }^{20}$ y lo vincula con la poética de T. S. Elliot: «The poet must become more and more comprehensible, more allusive, more indirect, in order to force, to dislocate if necessary, language into his mean» (Joshi, 2001: 247); en tanto que Santiago Eximeno encuentra en él un estilo exageradamente recargado. ${ }^{21}$ Sin embargo, como queda demostrado en los textos seleccionados, estas descripciones sirven para establecer transiciones y crear el efecto de una realidad fluctuante, como observa David Jasso:

Más allá de ser un mero decorado, el entorno que nos rodea se transforma en un lugar opresivo, ominoso, si me permite la palabra, repleto de multitud de pequeños detalles que lo forman y le otorgan singularidad.

\footnotetext{
19 «Mientras que, en la superficie, estas producciones parecían basarse en multitud de fuentes dudosas, cada una aseguraba tener los orígenes más realistas, según las palabras de Severini, su somniloquio, según ellos» (Ligotti, 2006: 266).

20 «[...] extraordinary subjects require a certain deviousness in the telling, that a twisted or obscure technique is needed to realize the maximum power of strange» (Joshi, 2001: 247).

21 «Todo lo dicho anteriormente hay que envolverlo en un lenguaje complicado, retorcido, untuoso y pretencioso. Si se disfraza de poesía oscura se obtiene el reconocimiento de los críticos y de los aficionados más recalcitrantes. No importa que no entienda bien o que el resultado sea pura incoherencia. Miren esta frase: "la lobreguez glacial de las cosas", mola, ¿eh? Piensen en ella, intentad interpretarla... es como tratar de interpretar el infinito» (Jasso, 2007: 42).
} 
Es en las descripciones del entorno (realizadas con breves pinceladas, como si el lector se detuviera un instante ante un lienzo y viera trabajar a un artista) donde los relatos adquieren profundidad. En el estilo descubrimos un ritmo lento, moroso, que convierte la sucesión de acontecimientos en una exposición pictórica, una serie de diapositivas estáticas que anula la acción, que anula al personaje, forzando la historia a una pausa, casi hasta detenerla (Jasso, 2007: 44).

La construcción de estas ficciones responde a las preocupaciones de finales del siglo XX («his work could only have been written by one sensitive to the ambiguities of his fin de siècle»; Joshi, 2001:247-248) y, como el propio autor ha expuesto, tienen al lenguaje como una de sus bases: «I'm really interested in style exclusively as an expression of a peculiar kind of consciousness as opposed to the mere gaudy use of language. [...] Style is the intersection between an author's choice of subject matter and what he does with that subject manner. This is what reflects a writer's consciousness and therefore his style» (Ayad, 2004).

Como se discierne en el camino inverso de la cadena de representaciones del material fantasmático, Ligotti está desplazando el miedo concreto para convertirlo en una angustia por lo informe, pretende escapar de la domesticación ${ }^{22}$ y al mismo tiempo seducir al lector con planteamientos de corte nihilista través de la literatura fantástica:

I do not know if this accurately represents Ligotti's philosophy, but it is an ideal instance of that intellectualized horror of which he is such a master. Somehow Andrew Maness is the embodiment of this nihilistic existentialism, and only Ligotti could have written so compellingly hypnotic a tale around such a dryly philosophical conception (Joshi, 2001: 256).

Para entender su concepción de la existencia como una pesadilla ${ }^{23}$ es necesario recurrir a las afirmaciones que ha hecho sobre la obra de Poe y de

22 "[En el fantaterror actual] El "bien" siempre triunfa, incluso cuando lo hace el "mal", ya que este ha sido completamente domesticado a través de arquetipos devenidos lugares comunes de una mitología cotidiana descafeinada, reificados como bienes de consumo para minorías aparentemente selectas — tribus urbanas y modernos de diverso pelaje-, o para mayorías bienpensantes — lectores de bestsellers prestigiados por suplementos dominicales-que, a la larga, se unen en un sólido mercado casi indistinguible (el joven gothic que lee Crepúsculo... mientras su madre ya va por el tercero de la saga)» (Palacios, 2012: 11).

23 Ligotti lo afirma en entrevista: «I Have a Special Plan for This World takes places in a corporate setting, but, like my other corporate horror tales, was intended to convey a broader perspective relating to themes that are important to me: the fiasco and nightmare of existence, the particular fiasco and nightmare of human existence, the sense that people are puppets of powers they cannot comprehend, etc.» (Cardin, 2006: s. p.). 
Lovecraft, sus dos grandes influencias, y la lección que toma de ambos escritores de que la sensación de condenación también debe alcanzar al lector:

En esta historia no importan las personas. En el universo literario de Poe (y en el de Lovecraft), lo individual es horrible y consoladoramente irrelevante. Durante la lectura de «La caída de la casa de Usher» no miramos por encima del hombro de ningún personaje, sino que nuestra atención se distribuye de modo omnisciente por las cuatro esquinas de una pestilente factoría que fabrica un solo producto: una perdición total de la que no hay escapatoria (Ligotti, 2006: 19).

Como ha señalado Joshi, lo que separa a Ligotti de H. P. Lovecraft, es que, mientras que Lovecraft intenta hacer lo irreal real, el «escritor de prosas nihilistas», como se autodenomina el protagonista de «Teatro Grottesco, hace que lo real se torne irreal (Joshi, 2001: 243-250).

Si como hemos visto, la casa encantada es el universo y un rasgo humano es la distinción de lo sobrenatural, ${ }^{24}$ la propuesta estética de Thomas Ligotti va más allá de la caracterización que Roger Bozzeto hace de la literatura fantástica frente a la realidad:

Lo fantástico es texto. En la realidad, pueden existir momentos de ambigüedad ante la realidad que no coincide con mi expectativa, mis costumbres, pero esto no dura: puedo no reconocerme en el espejo, o tomar durante un instante el maniquí por un hombre, o ver en la bruma una forma desconocida, pero pongo rápidamente las cosas en su sitio. En la realidad, lo fantástico, ese efecto desordenado que me hace bascular entre el vértigo o el malestar ante la no coincidencia de lo familiar con su representación, existe pero no dura: la razón oscila pero no zozobra (Bozzetto, 2001: 240-241).

Porque en Ligotti las fronteras que dividen a las categorías son indiscernibles; la razón ni oscila ni tampoco zozobra, porque simplemente no hay razón, sino un continuum.

24 «El más fenomenal de los rasgos humanos —el sentido de lo sobrenatural, la impresión de un distanciamiento fatal de lo visible- depende de nuestra mente» (Ligotti, 2007: 49).
} 
BiBLIOGRAFÍA

AYAD, Neddal (2004): «Literature Is Entertainment or It Is Nothing. An Interview with Thomas Ligotti», en Fantastic Metropolis, disponible en -http://www.fantasticmetropolis.com/i/ligotti// — [fecha de la consulta: 15 de noviembre de 2012].

Bellemin-NoËL, Jean (2001): «Notas sobre lo fantástico (Textos de Théophile Gautier)», en David Roas (comp.), Teorías de lo fantástico, Arco/Libros, Madrid, pp. 107-140. (2002): «Lo fantástico y el inconsciente», en David Roas (coord.), Lo fantástico: literatura y subversión, monográfico de Quimera, núms. 218-219, pp. 51-56.

BozzetTo, Roger (2001): «¿Un discurso de lo fantástico?», en David Roas (comp.), Teorías de lo fantástico, Arco/Libros, Madrid, pp. 223-242.

(2002): «El sentimiento de lo fantástico y sus efectos», en David Roas (coord.), Lo fantástico: literatura y subversión, monográfico de Quimera, núms. 218-219, pp. 35-40.

CARDin, Matt (2000): «Thomas Ligotti's Career of Nightmares», en The Art of Grim Scribe, disponible en —http://www.angwa.de/Ligotti/essay/essay_cardin_e. htm - [fecha de la consulta: 15 de noviembre de 2012]; también se incluye en Darrell Schweitzer (ed.), The Thomas Ligotti Reader. Essays and Explorations, Wildside Press, Pensilvania 2003, pp. 12-22.

(2003): «Liminal Terror and Collective Identity in Thomas Ligotti's The Shadow at the Bottom of the World», en Darrell Schweitzer (ed.), The Thomas Ligotti Reader. Essays and Explorations, Wildside Press, Pensilvania, pp. 85-100.

(2006): «It's All a Matter of Personal Pathology: An Interview with Thomas Ligotti», en The Teeming Brain, 2006, disponible en - http://theteemingbrain. wordpress.com/interview-with-thomas-ligotti/— [fecha de la consulta: 15 de noviembre de 2012]. La primera edición en The New York Review of Science Fiction, issue 218, vol. 19, núm. 2, octubre de 2006.

Dziemianowicz, Stefan R. (2003): «Nothing is What It Seems to Be», en Darrell Schweitzer (ed.), The Thomas Ligotti Reader. Essays and Explorations, Wildside Press, Pensilvania, pp. 38-52.

Ligotтi, Thomas (1989): «La última aventura de Alicia», en Douglas E. Winter (comp.), Pesadilla, Grijalbo, Barcelona, pp. 143-169.

(2003): «The Dark Beauty of Unheard-of Horrors», en Darrell Schweitzer (ed.), The Thomas Ligotti Reader. Essays and Explorations, Wildside Press, Pensilvania, pp. 78-84.

(2006): La fábrica de pesadillas, La Factoría de ideas, Madrid.

(2007): La fábrica de pesadillas [Cómic], Panini Comics, Barcelona.

JAsso, David y Santiago Eximeno (2007): «Críticas enfrentadas: La fábrica de pesadillas», Revista Hélice, núm. 2, pp. 40-45, disponible en —http://www.revistahelice.com/- [fecha de la consulta: 4 de febrero de 2011].

Joshi, T. S. (2001): «Thomas Ligotti: The Escape from Life», en The Modern Weird Tale, McFarland \& Company, Carolina del Norte. Incluido también en Darrell Schweitzer (ed.), The Thomas Ligotti Reader. Essays and Explorations, Wildside Press, Pensilvania, 2003, pp. 135-153.

OrTIZ, Daniel (2010): «Thomas Ligotti. Un recorrido por la obra de este enigmático 
escritor», en Insomia. El universo de Stephen King, disponible en —http://www. stephenking.com.ar/revista/154/otrosmundos.htm— [fecha de la consulta: 15 de noviembre de 2012].

Palacios, Jesús (2012): «Pasos en la oscuridad. Un atisbo al horror según Thomas Ligotti», en Thomas Ligotti, Noctuario. Relatos extraños y terroríficos, Valdemar, Madrid, pp. 9-18.

ROAs, David (2001): «La amenaza de lo fantástico», en David Roas (comp.), Teorías de lo fantástico, Arco/Libros, Madrid, pp. 7-44

(coord.) (2002): Lo fantástico: literatura y subversión, monográfico de Quimera, núms. 218-219.

(2006): «Hacia una teoría sobre el miedo y lo fantástico», Semiosis (México, Universidad Veracruzana), núm. 3, pp. 95-116.

(2008): «¿La realidad está ahí afuera? El lugar de lo fantástico en la narrativa posmoderna», Quimera, núm. 301, pp. 75-79.

Schweitzer, Darrell (ed.) (2003): The Thomas Ligotti Reader. Essays and Explorations, Wildside Press, Pensilvania. 